\title{
Interleukin-2 Anti-Idiotype Vaccine
}

National Cancer Institute

\section{Source}

National Cancer Institute. Interleukin-2 Anti-Idiotype Vaccine. NCI Thesaurus. Code C29112.

A vaccine based on anti-idiotype (Id) monoclonal antibodies combined with interleukin-2 (IL-2). Anti-Id vaccines have been shown to be effective in treatment of B-cell lymphoma in animal models and in clinical trials, resulting in tumor regression; the addition of interleukin-2 (IL-2) may augment the therapeutic effect of anti-Id vaccines. (NCI04) 